\title{
DIELECTRIC RF RESONATORS WITH OPEN BOUNDARIES FOR STUDYING RADIATION EFFECT ON ELECTRODYNAMIC CHARACTERISTICS OF SOLID DIELECTRICS
}

\author{
V.A. Kushnir, K.Yu. Kramarenko, V.V. Mytrochenko, O.D. Nikitina, S.A. Perezhogin, \\ L.I. Selivanov \\ National Science Center "Kharkov Institute of Physics and Technology", Kharkiv, Ukraine \\ E-mail: kushnir@kipt.kharkov.ua
}

The use of dielectric materials in the charged particles accelerators requires investigation of changes in the electrodynamic properties of these materials under the influence of ionizing radiation. First of all it is necessary to study the effect of radiation on the complex dielectric permittivity ( $\varepsilon$ and $\operatorname{tg} \delta$ ) of these materials. The actual task is to measure very small relative changes in the dielectric constant, for example, $\Delta \varepsilon / \varepsilon \sim 10^{-4}$. Such accuracy can be provided by resonator methods. In the present work results of theoretical and experimental research of microwave dielectric resonators with open boundaries are given. It is shown, that they can be used to measure dielectrics during irradiation by gamma radiation or charged particles beam. The analysis of factors that affect the accuracy of measurements is carried out.

PACS: 84.90.+a, 85.50-n,77.90.+k,29.20.-c

\section{INTRODUCTION}

Further development of accelerator technology is associated with the search for new methods charged particle beams acceleration. One of the directions of these studies is based on the use of dielectric materials [1]. This applies both to acceleration methods in wake fields, excited by electron bunches [2, 3], and to new dielectric-assist accelerating structures with the traditional RF power input [4]. Dielectrics for accelerating structures will be operated under conditions of strong ionizing radiation. Therefore, detailed study of the effect of radiation on the electrodynamics properties of materials at microwave frequencies is required. The study of the behavior of dielectrics during irradiation (in situ) $[5,6]$ is of interest. The main purpose of our work is to develop methods and devices allowing to conduct such research.

It is known that the most accurate method for measurement of changes in the real part of permittivitye and the dielectric loss tangent $\operatorname{tg} \delta$ at microwave is resonatorbased method. Various types of open RF dielectric resonators to be most suitable for this purpose are known.

The present article describes the results of the study of resonance systems that provide information about the change in dielectric characteristics of dielectrics at their irradiation with charged particles or gamma radiation.

\section{CALCULATIONS AND SIMULATION}

The waveguide-dielectric resonator and its modification, as well as an open resonator "dielectric disk on a conducting plane" Fig. 1 wereconsidered. The principle of operation of waveguide-dielectric resonators with open boundaries is as follows. Dielectric sample with relative permittivity $\varepsilon$ is installed in a microwave transmission line (waveguide or radial line), in which waveguide modes do not propagate at a given frequency $\mathrm{f}_{0}$ (wavelength $\lambda_{0}$ is more than cut-off wavelength $\lambda_{\mathrm{c}}$ ). If $\varepsilon>\left(\lambda_{0} \lambda_{c}\right)^{2}$, resonance oscillations can be excited in the sample under certain conditions (shape and size of the dielectric). In this case the energy of these oscillations is concentrated mainly in the dielectric.

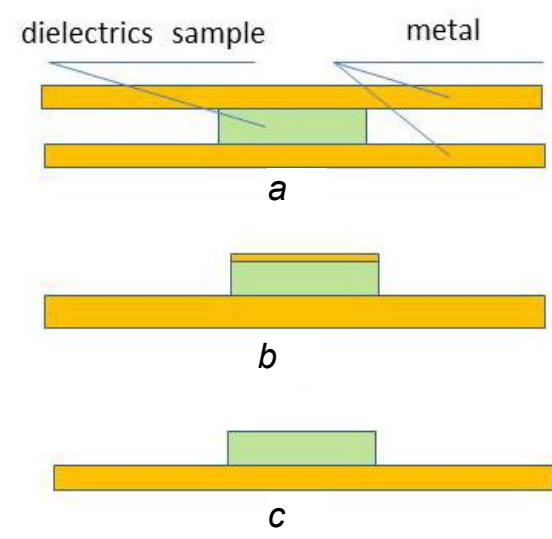

Fig. 1. Waveguide-dielectric resonator (a); modified waveguide-dielectric resonator (b); open resonator

"dielectric disk on a conducting plane" (c)

The eigenfrequencies of resonator are determined by its geometry and dielectrics permittivity. The possibility to use such a resonator to measure the dielectric constant and the loss tangent was first proposed and described in [7]. This method has been improved and successfully applied for experimental studies on the dielectrics properties of different materials (see, for example, $[8,9])$. The resonator under consideration is formed by dielectric disk between two conducting planes (radial line). Obviously, the magnetic modes (TE) should be chosen for measurements. The most suitable is the $\mathrm{TE}_{011}$ type, which has only the azimuthal component of the electric field. This choice can significantly reduce the effect of contacts between the dielectric and the metal planes on the resonant frequency and quality factor.

The characteristic equation that relates the dimensions and permittivity of the dielectric $\varepsilon$ to the eigenfrequencies $\mathrm{f}_{\mathrm{r}} \mathrm{TE}_{0 \mathrm{nl}}$ modes can be written in the form [8].

$$
\begin{gathered}
\alpha \frac{J_{0}(\alpha)}{J_{1}(\alpha)}=-\beta \frac{K_{0}(\beta)}{K_{1}(\beta)}, \\
\alpha=\frac{\pi D f_{r}}{c} \sqrt{\varepsilon-\left(\frac{l c}{2 L f_{r}}\right)^{2}},
\end{gathered}
$$




$$
\beta=\frac{\pi D f_{r}}{c} \sqrt{\left(\frac{l c}{2 L f_{r}}\right)^{2}-1},
$$

where $\mathrm{D}$ and $\mathrm{L}$ are the diameter and thickness of the dielectric disk, $\mathrm{c}$ is the speed of light, $\mathrm{J}_{0}(\alpha)$ and $\mathrm{J}_{1}(\alpha)$ are the Bessel functions of the first kind, $\mathrm{K}_{0}(\beta)$ and $\mathrm{K}_{1}(\beta)$ are the modified Bessel functions of the second kind. The characteristic function has an infinite number of zeros and an infinite number of discontinuities of the second kind. The value $n=1$ corresponds to the first zero of the characteristic equation.

The unloaded Q-factor $\mathrm{Q}_{0}$ of resonator is determined by the value of losses both in the dielectric disc and in metal planes with finite conductivity. The dielectric loss tangent for the resonator can be determined from the expression [7]:

$$
\operatorname{tg} \delta=\frac{A}{Q_{0}}-B,
$$

where

$$
\begin{aligned}
& A=1+\frac{F(\alpha) G(\beta)}{\varepsilon} ; \\
& B=\frac{c^{2}}{2 f_{r}^{2} \varepsilon L^{3}} \cdot \frac{1}{\sqrt{\pi f_{r} \mu_{0} \sigma}}(1+F(\alpha) G(\beta)) ; \\
& F(\alpha)=\frac{J_{1}^{2}(\alpha)}{J_{1}^{2}(\alpha)-J_{0}(\alpha) J_{2}(\alpha)} \\
& G(\beta)=\frac{K_{0}(\beta) K_{2}(\beta)-K_{1}^{2}(\beta)}{K_{1}^{2}(\beta)} .
\end{aligned}
$$

The second summand $B$ depends on the surface resistance of the metal. If $\mathrm{B}=$ Const (contact properties do not change), the measurement of tg $\delta$ change under radiation can be easily done by measuring of change in the quality factor of the resonator. Thus, making use these expressions, the values $\varepsilon$ and $\operatorname{tg} \delta$ can be calculated using measured resonator parameters $\mathrm{f}_{\mathrm{r}}$ and $\mathrm{Q}_{0}$. On the other hand, there are a number of computational programs, which allow to sumulate different electrodynamics systems and determine their characteristics with high accuracy. The calculations and simulation for $\mathrm{TE}_{011}$ mode resonator with the dielectric sample - a disk with diameter of $32 \mathrm{~mm}$ and height of $6 \mathrm{~mm}$ located between copper plates (the specific conductivity $5.8 \cdot 10^{7} \mathrm{~S} / \mathrm{m}$ ) have been carried out (Fig. 2). The difference between the results of calculations by formula (1) and simulation does not exceed $10^{-3}$. The strong dependence of resonance frequency on the permittivity allows to measure very small change of $\varepsilon$. So, for example, at $\varepsilon=90$ $\varepsilon \frac{\partial f}{\partial \varepsilon}=-13.5 \mathrm{MHz} / \%$. If no other factors that influence on the resonance frequency, the relative permittivity change $10^{-4}$ can be measured.

As a result of calculations, the dependencies of $\mathrm{TE}_{011}$ mode frequency on the size of the dielectric sample were determined. In particular, at $\varepsilon=90, D=16 \mathrm{~mm}$ and $\mathrm{L}=6 \mathrm{~mm}$, frequency change due to change of radius and height are equal to -20.0 and $-340 \mathrm{MHz} / \mathrm{mm}$ accordingly. The height of the sample influences most strongly on the value of the resonance frequency. Therefore, special attention should be paid to careful surface treatment of both metal elements and dielectric sample.

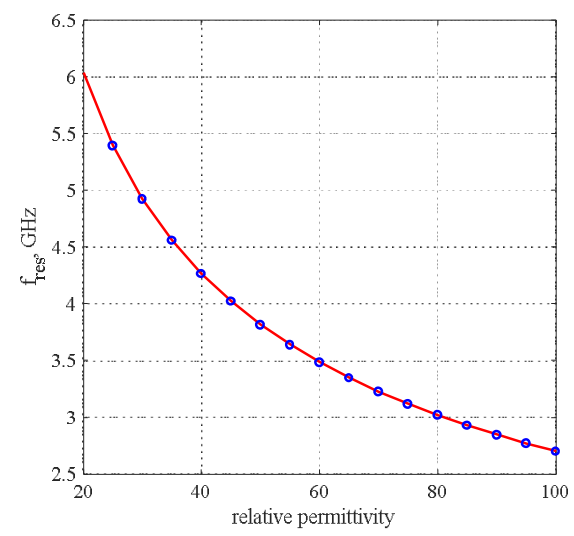

Fig. 2. Dependence of the $T E_{011}$ mode frequency on permittivity. The solid curve - calculation according to formula (1); the circles - the simulation results

Calculated by formula (2) dependence of the unloaded Q-factor on the dielectric loss tangent $(\operatorname{tg} \delta)$ is shown in Fig. 3. Note that, Q-factor over $10^{2}$ is easily measured by the well-known microwave measurement methods. The picture shows that the accuracy of $\operatorname{tg} \delta$ determination by measured $\mathrm{Q}_{0}$ is decreases essentially with decrease of the dielectric losses in dielectric sample due to the presence of losses in the metallic planes. It limits the possibility to use this type of resonator for investigation of dielectric losses variation in dielectrics with $\operatorname{tg} \delta \sim 10^{-5}$.

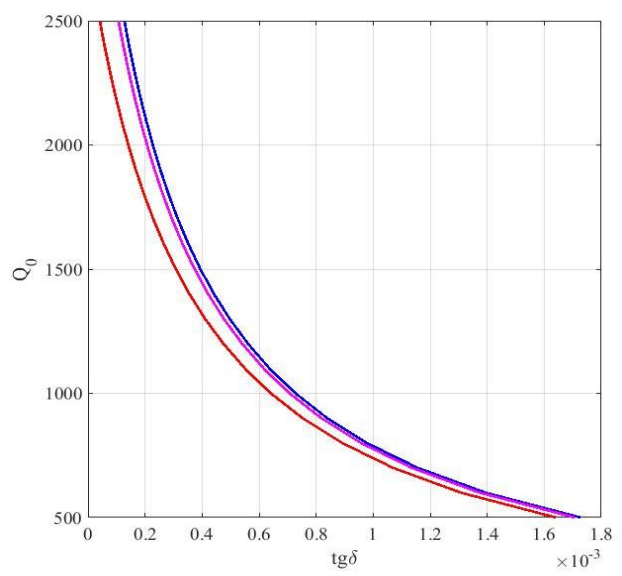

Fig. 3. Blue $-\varepsilon=30$ (4929.9 MHz); magenta $-\varepsilon=40$

(4269.7 MHz); red $-\varepsilon=90(2846.8 \mathrm{MHz})$;

specific conductivity $-5.8 \cdot 10^{7} \mathrm{~S} / \mathrm{m}$

The strongest factor that affects the performance of any microwave resonator is temperature. In metal RF cavities, frequency shifts depends only on thermal linear expansion of the metal. In case of dielectric resonators, the additional factor is the temperature dependence of dielectric permittivity. For most ceramic materials, the coefficient of linear expansion is $(3 \ldots 5) \cdot 10^{-6} \mathrm{~K}^{-1}$. At $\varepsilon=90$, taking into account the above dependence of frequency on the sample dimensions, the change in frequency $\mathrm{TE}_{011}$ mode, due to the thermal expansion is $-1.2 \cdot 10^{-2} \mathrm{MHz} \cdot \mathrm{K}^{-1}$. For different types of ceramics, the value of the thermal change in permittivity can vary both in sign and value within a large range. This dielectrics characteristic must therefore be measured experimentally in each case. In addition, it is well known that dielectric losses in ceramics of different types depend on temperature. The nature and magnitude of this de- 
pendence is determined by various factors - chemical composition, crystal structure, ceramics technology, etc.

The resonator of considered type can be used for investigation of influence of charged particles beams and gamma radiation on dielectric properties of dielectric. However, the presence of a metal disk, which faces the source of radiation, limits the possibilities of the method in the field of low energies particles. The desire to reduce the thickness of this disk leads to problems with contact between dielectric and metal. Therefore we have considered variant of the waveguide dielectric resonator in which the diameter of the upper disk is equal to the diameter of the dielectric sample and the thickness exceeds in several times of the skin depth, which is several microns in our frequency range. The making this resonator requires coating of the dielectric sample with a thin layer of metal with good conductivity, such as silver, copper or gold.

The simulation result showed that in the range of the permittivity change $(\varepsilon=30 \ldots 120)$, the $\mathrm{TE}_{011}$ mode frequency slightly (not more than $1 \cdot 10^{-3}$ ) differs from the resonance frequency of a resonator with two metal disks that is described above. The dependence of the resonant frequency on the permittivity value also remains practically unchanged. However, the Q-factor is about 25\% less than that of a resonator (a) in Fig. 1.

Open resonators of the type dielectric disk on the conductive plane (see Fig. 4) is a well-known electrodynamic structure, which is used mainly as microwave filters and radiators of the antennas of the centimeter range $[10,11]$. From the point of view of the study of changes in the properties of dielectrics under irradiation, the use of such resonators is necessary in the case of irradiation with low-energy particles that lead to the surface or volume charging of the dielectric.

In such a system TE, TM, and hybrid (EH and HE) modes can be excited. They are determined as follows: $\mathrm{TE}_{0 \mathrm{pm}+\Delta}, \mathrm{TM}_{0 \mathrm{pm}+\Delta}, \mathrm{HE}_{\mathrm{npm}+\Delta}, \mathrm{EH}_{\mathrm{npm}+\Delta}$. The value $\Delta$ varies from 0 to 1 , and is close to 1 at large $\varepsilon$ [11]. To study the effects of radiation on the dielectric, it is advisable to use TE modes, in particular $\mathrm{TE}_{011+\Delta}$. We have performed appropriate simulation of the open resonator. The dielectric sample, which was used in simulation, was a disk with $\mathrm{D}=32 \mathrm{~mm}$ and $\mathrm{L}=6 \mathrm{~mm}$. Two methods of resonator excitation have been considered in such simulation. One of them is carried out by coaxial probes (see Fig. 4), the other one uses symmetric slot line. The results of calculations of the resonator parameters at different excitation methods coincided.

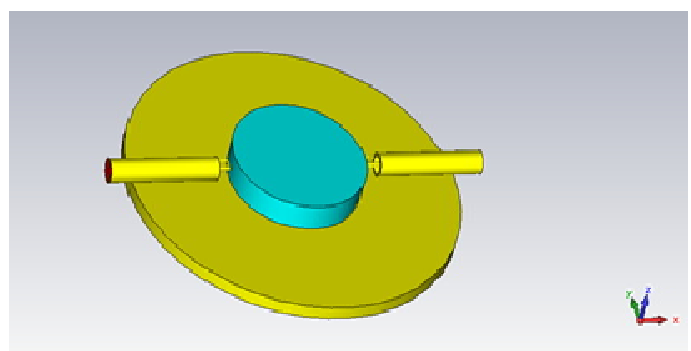

Fig. 4. Open resonator with coaxial probes

As a result of the simulation, the dependence of the $\mathrm{TE}_{011+\Delta}$ mode frequency on the permittivity and the distribution of the electromagnetic field both in and out of the dielectric (Figs. 5 and 6) were determined. So, for example, at $\varepsilon=90 \varepsilon \frac{\partial f}{\partial \varepsilon}-10.4 \mathrm{MHz} / \%$.

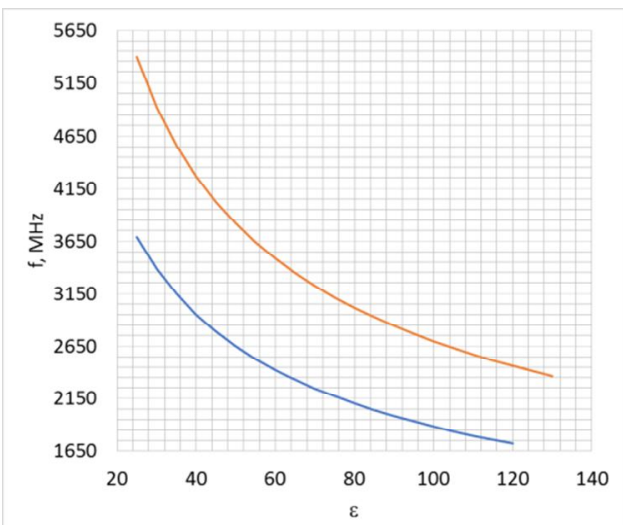

Fig. 5. Upper curve - waveguide dielectric resonator ( $T E_{011}$ mode), lower curve - open resonator

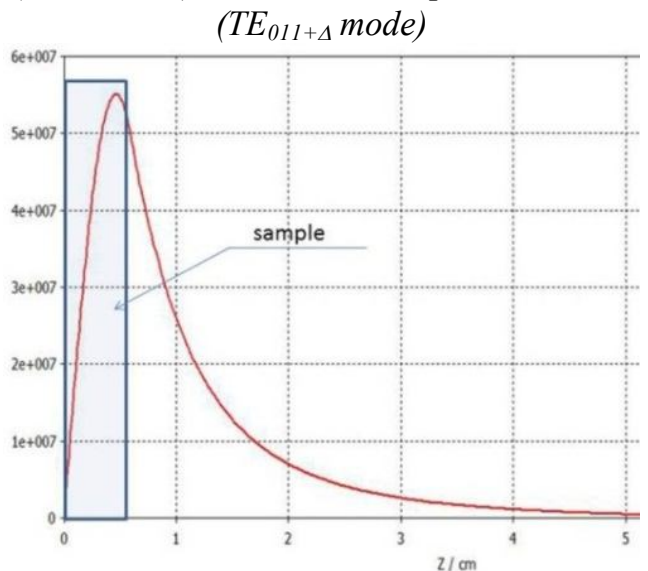

Fig. 6. Dependence of the azimuthal component of the electric field on the longitudinal coordinate $E(z) a t r=8 \mathrm{~mm}$. The height of the sample is $6 \mathrm{~mm}$

It can be seen that much of the electric field is observed outside the dielectric sample.

\section{EXPERIMENTAL DATA AND DISCUSSION}

Experimental study of resonator properties, which are described above, was carried out using titanium ceramics. Discs with a diameter of about $32 \mathrm{~mm}$ were cut out of a $6 \mathrm{~mm}$ thick ceramic plate with a diamond tool (Fig. 7).

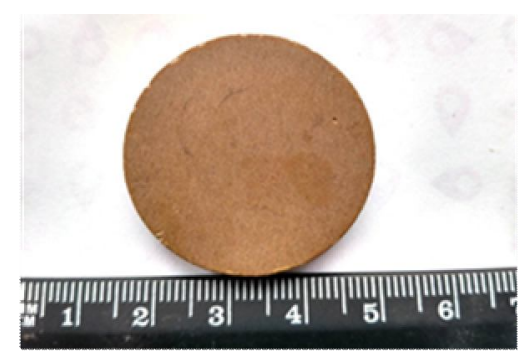

Fig. 7. Titanium ceramic sample

Flat surfaces of the dielectric sample were polished; deviations in thickness of the sample do not exceed $10 \mu \mathrm{m}$. Some of the samples were covered with a layer of silver about $30 \mu \mathrm{m}$ thick. The ceramics permittivity was measured in advance. For frequency of $1 \mathrm{MHz}$, the result was $\varepsilon=95$. For study the waveguide-dielectric resonator the dielectric disk was placed between two metal $80 \mathrm{~mm}$ diameter discs made of oxygen-free cop- 
per. The contact surface of the copper discs was machined with a diamond tool. One of the copper discs was only $1.5 \mathrm{~mm}$ thick at the dielectric contact aria. This makes it possible to irradiate the dielectric with electrons with energy in tens of Megaelectronvolt without significant changes in the energy and intensity of the beam. The excitation of the resonator was carried out by coaxial induction probes. The coaxial probes do not contain the organic materials, which have low level of radiation resistance. Coaxial to resonator coupling factors were chosen much less than 1and they did not affect either the resonance frequency or the Q-factor of the resonator.

The resonance frequencies and Q-factor of the resonator were measured with HP 8753C circuit analyzer in the frequency range of $1.5 \ldots 3 \mathrm{GHz}$. Preliminary all dimensions of the resonator were carefully measured. The data from these measurements were used in calculations and in simulations. By comparing the experimental results and calculated data, different modes were identified and the value of ceramic permittivity in this frequency range was determined.

In the first stage, the parameters of the waveguidedielectric resonator (see Fig. 1,a) were measured. Experimentally measured resonance frequency $\mathrm{TE}_{011}$ mode was $2819.8 \mathrm{MHz}$, which corresponds to relative permittivity of $91 \pm 0.5$. The Q-factor of the resonator is $890 \pm 50$. Using the calculated data (see Fig. 3), it can be argued that the $\operatorname{tg} \delta=(9 \pm 0.6) \cdot 10^{-4}$. These basic ceramics parameters were used to model other types of resonators.

To study the modified waveguide-dielectric resonator (see Fig. 1,b) we used samples of ceramics, which were covered with silver. The thickness of the silver coating was about $30 \mu \mathrm{m}$. The dielectrics sample under study and the resonator are shown in the Fig. 8.
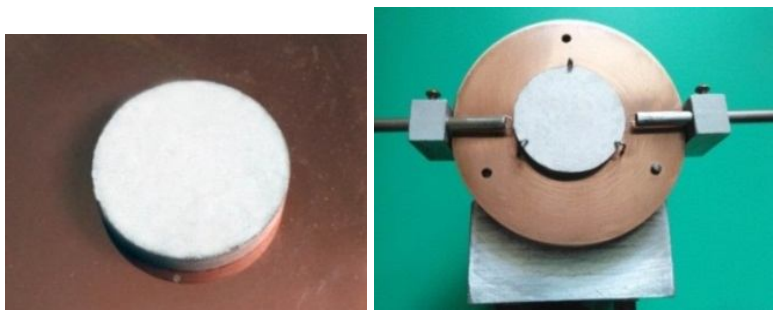

Fig. 8. Dielectric sample coated with silver on cupper plane and dielectric resonator with coaxial probes

Measurements have shown satisfactory correspondence between experimental data and simulation results. In particular, as can be seen from the Fig. 9, the measured frequency of the $\mathrm{TE}_{011}$ mode is $2899.3 \mathrm{MHz}$, and the simulation frequency is $(2901.7 \pm 1.2) \mathrm{MHz}$. Measured Q-factor of the resonator is $580 \pm 40$ (calculated value is 670).

The biggest difficulty in experimental investigation of the open resonator (see Fig. 1,c) was identification of modes. To solve this problem we developed a measuring complex Fig. 10, which allows determining in automatic mode electric field distribution over the surface of the dielectric sample by the perturbation method. Symmetric slot line was used for the resonator excitation.

The Fig. 11 shows the measurement results for $\mathrm{TE}_{011+\Delta}$ mode (no azimuth variation in the electric field). The experiments showed satisfactory agreement be- tween the calculated and experimental data. Thus, the calculated value of the $\mathrm{TE}_{011+\Delta}$ mode resonance frequency at $\varepsilon=91$ is $(1995.6 \pm 0.9) \mathrm{MHz}$, and the measured value is $1991.0 \mathrm{MHz}$.
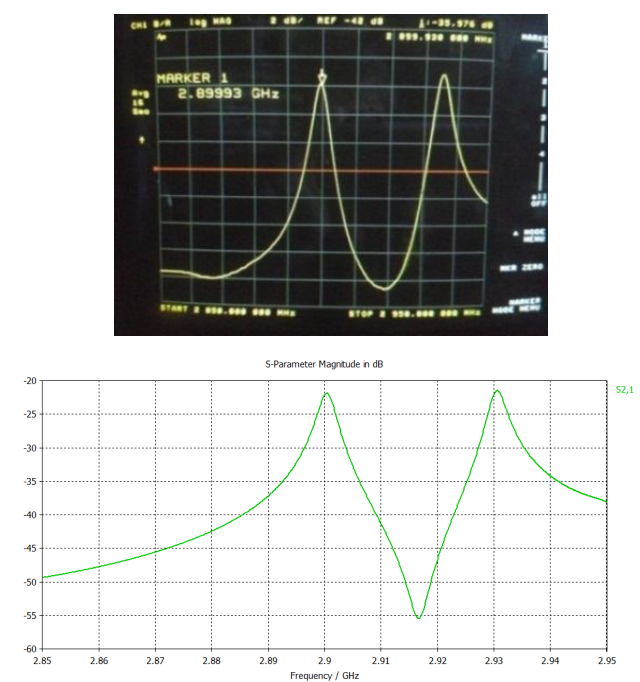

Fig. 9. Frequency dependence of transmission factor $S_{21}$. At the top-experiment, photo from display HP 8753C, at the bottom - simulation result at $\varepsilon=91$

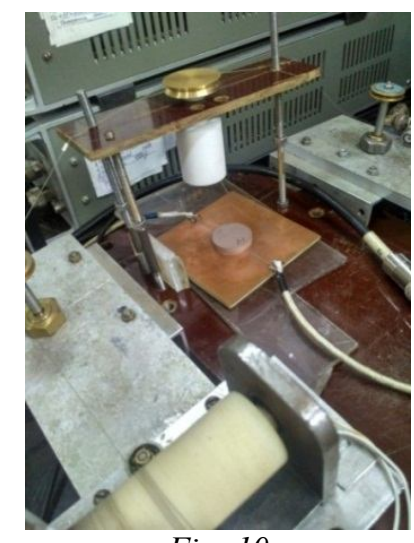

Fig. 10

$\mathrm{F}=1991 \mathrm{MHz}$

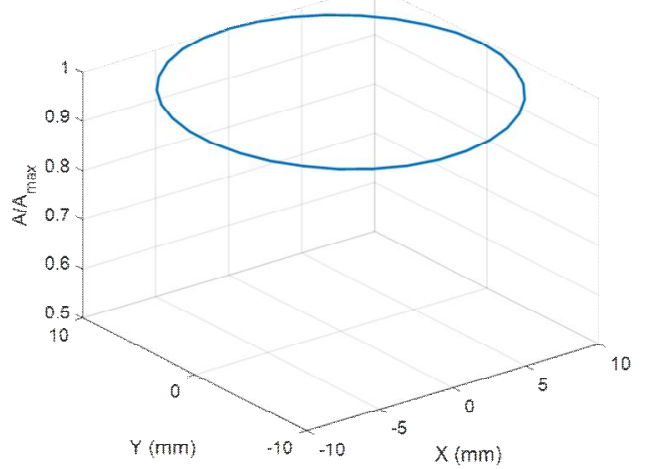

Fig. 11. The electric field distribution at a distance of $2 \mathrm{~mm}$ from dielectric disk surface and $r=10 \mathrm{~mm}$

It is well known that temperature has a significant effect on the dielectric parameters. Thus, as the temperature increases, the dielectric losses increase for almost all dielectrics due to an increase of thermal conductivity. As for the dielectric permittivity, the value and sign of its change with temperature depends on many factors, mainly on the type of polarization and frequency. To study the dependence of $\mathrm{TE}_{011}$ mode resonance frequency on temperature appropriate measurements for the 
types of resonators under consideration have been carry out. The measurements have showed that in all three cases the resonance frequency increases with temperature, i.e. the temperature coefficient of the permittivity is negative for this material. This is typical for titanium oxide-based ceramics. The resonant frequency in a range of temperature change $20 \ldots 70^{\circ} \mathrm{C}$ linearly depends on temperature and it is accordingly $+1.34,+1.24$, and $+0.98 \mathrm{MHz} \cdot \mathrm{K}^{-1}$ for resonators in Fig. 1,a,b,c. This is substantially greater than the frequency shift caused by linear thermal expansion. The Fig. 12 shows the measured dependence of the dielectric permittivity on temperature for the ceramic sample in the case of the waveguidedielectric resonator in Fig. 1,a.

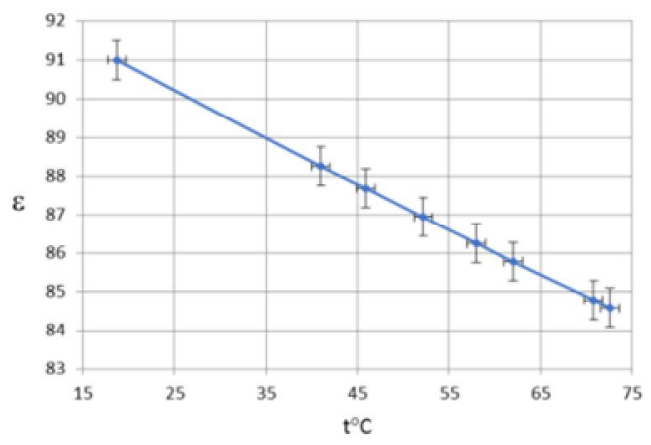

Fig. 12. Temperature dependence of titanium ceramics permittivity at frequency of $2820 \mathrm{MHz}$

Q-factor of resonators decreases with temperature. However, this dependence is different for each resonator. The relative change in Q-factorin the range of $20 \ldots 70^{\circ} \mathrm{C}$ is $-36 \%,-32 \%$, and $-21 \%$ for Fig. $1, a, b$, and c resonators.

The calculations and measurements of the Q-factor have showed that they are different for different types of resonators. Measured Q-factor for resonators a), b) and c) is $890 \pm 50,580 \pm 40$ and $320 \pm 30$ respectively. This phenomenon can be explained by studying the mechanisms of high-frequency power loss in these resonators. Let us assume that the coupling factor of the resonator with coaxial probes is much less than 1 . Then total power $(\mathrm{P})$ lost can be divided into two components: radiated power $\left(\mathrm{P}_{\mathrm{rad}}\right)$ and power dissipated as heat in dielectric and metal $\left(\mathrm{P}_{\mathrm{dis}}\right)$. Open resonators used in the antennas operate as a rule on $\mathrm{TM}_{110}$ mode, have a dipole field component and $\mathrm{P}_{\mathrm{rad}}>>\mathrm{P}_{\text {dis. }}$. In the waveguidedielectric resonator there is no radiation loss, because the evanescent waves attenuate quickly as $\mathrm{r}$ increases. However, for resonators b) and c), despite the axial symmetry of the field, there are radiation losses, which is the reason for the reduction of unloaded Q-factor.

\section{CONCLUSIONS}

All resonators considered in work can be used for investigation of radiation influence on dielectrics in microwave range. The most complete and reliable information can be obtained with waveguide dielectric resonator, which has the following advantages: convenience of interpretation of measurement results and absence of radiation losses. By measuring at higher modes, it is possible to obtain information about changes in the dielectric characteristics in the frequency range of several $\mathrm{GHz}$ on the same sample. If it is neces- sary to research the effect of dielectric surface charging, it is possible to use an open resonator with careful simulation, including microwave power radiation. The main factor influencing on the accuracy of determination of dielectric parameters change during irradiation is instability of sample temperature, which can be caused, for example, by a beam of charged particles. Therefore, it is necessary to make preliminary measurements of the resonance frequency and Q-factor dependence on temperature and to measure the temperature of the sample during irradiation. If these conditions are met, a change in the dielectric constant $\Delta \varepsilon / \varepsilon \sim 10^{-3}$ during irradiation can be measured.

\section{REFERENCES}

1. C. Jing. Dielectric wakefield accelerators // Reviews of Accelerator Science and Technology. 2016, v. 09, p. 127-149.

2. V.A. Balakirev, I.N. Onishchenko, D.Yu. Sidorenko, G.V. Sotnikov. Charge particle accelerated by wakefields in a dielectric resonatorwith exiting electron bunch channel // Technical Physics Letters. 2003, v. 29, № 7, p. 589-591.

3. K. Lekomtsev, A. Arishev, A.A. Tishchenko, M. Shevelev, A. Lyapin, S. Boogert, P. Karataev, N. Terunuma, J. Urakava. Driver-witness electron beam acceleration in dielectric mm-scale capillaries // Physical Reviev Accelerators and Beams. 2018, v. 21, 051301.

4. D. Satoh, M. Yoshida, and N. Hayashizaki. Fabrication and cold test of dielectric assist accelerating structure // Phys. Rev. Accelerators and Beams. 2017, v. 20, 091302.

5. Joshua L. Hodges, JR Dennison, Justin Dekany, Gregory Wilson, Amberly Evans, and Alec M. Sim. In Situ Surface Voltage Measurements of Dielectrics Under Electron Beam Irradiation // IEEE Trans. on Plasma Sci. 2014, v. 42(1), p. 255-265.

6. S.V. Shchelkunov, T.C. Marshall, J.L. Hirshfield. Real-time diagnostic for charging and damage of dielectrics in accelerators // Nuclear Instruments and Methods in Physics Research A. 2016, DOI 10.1016/j.nima. 2016.02.014.

7. B.W. Hakki and P.D. Coleman. A Dielectric Resonator Method of Measuring Inductive Capacities in the Millimeter Range // IRE Transaction on microwave theory and techniques. 1960, p. 402-410.

8. William E. Courtney. Complex Permittivity of GaAs and CdTe at Microwave Frequency // IEEE Trans. on Microwave Theory and Techniques. 1977, v. MMT-25, № 8, p. 697-701.

9. William E. Courtney. Analysis and Evaluation of a Method of Measurement the Complex Permittivity and Permeability of Microwave Insulators // IEEE Trans. on Microwave Theory and Techniques. 1970, v. MMT-18, № 8, p. 476-485.

10. S.A. Long, M.W. McAllister and L.C. Shen. The resonant cylindrical dielectric cavity antenna // IEEE Trans. Antennas Propagation. 1983, v. 31, p. 406-412.

11. L. Huitema and T. Monediera. Dielectric Materials for Compact Dielectric Resonator Antena http:/dx.doi.org/10.5772/50612.

Article received 24.02.2020 


\section{ДИЭЛЕКТРИЧЕСКИЕ СВЧ-РЕЗОНАТОРЫ С ОТКРЫТЫМИ ГРАНИЦАМИ ДЛЯ ИЗУЧЕНИЯ ВЛИЯНИЯ ИЗЛУЧЕНИЯ НА ЭЛЕКТРОДИНАМИЧЕСКИЕ ХАРАКТЕРИСТИКИ ТВЕРДЫХ ДИЭЛЕКТРИКОВ}

\section{В.А. Кушнир, К.Ю. Крамаренко, В.В. Митроченко, О.Д. Никитина, С.А. Пережсоин, Л.И. Селиванов}

Использование диэлектрических материалов в ускорителях заряженных частиц требует исследования изменения электродинамических свойств этих материалов под действием ионизирующего излучения. В первую очередь необходимо изучить влияние излучения на комплексную диэлектрическую проницаемость ( $\varepsilon$ и $\operatorname{tg} \delta$ ) этих материалов. Актуальной задачей является измерение малых относительных изменений диэлектрической проницаемости, например, $\Delta \varepsilon / \varepsilon \sim 10^{-4}$. Такая точность может быть обеспечена резонаторными методами. Приведены результаты теоретических и экспериментальных исследований СВЧ-диэлектрических резонаторов с открытыми границами. Показано, что они могут быть использованы для измерения параметров диэлектриков при облучении гамма-излучением или пучком заряженных частиц. Проведен анализ факторов, влияющих на точность измерений.

\section{ДІЕЛЕКТРИЧНІ НВЧ-РЕЗОНАТОРИ З ВІДКРИТИМИ ГРАНИЦЯМИ ДЛЯ ДОСЛІДЖЕННЯ РАДІАЦІЙНОГО ВПЛИВУ НА ЕЛЕКТРОДИНАМІЧНІ ХАРАКТЕРИСТИКИ ТВЕРДИХ ДІЕЛЕКТРИКІВ}

\section{В.А. Куинір, К.Ю. Крамаренко, В.В. Митроченко, О.Д. Нікітіна, С.О. Пережогін, Л.І. Селіванов}

Використання діелектричних матеріалів у прискорювачах заряджених частинок вимагає дослідження зміни електродинамічних властивостей цих матеріалів під дією іонізуючого випромінювання. В першу чергу необхідно вивчити вплив випромінювання на комплексну діелектричну проникність ( $\varepsilon$ i $\operatorname{tg} \delta)$ цих матеріалів. Актуальним завданням $є$ вимір малих відносних змін діелектричної проникності, наприклад, $\Delta \varepsilon / \varepsilon \sim 10^{-4}$. Така точність може бути забезпечена резонаторними методами. Наведено результати теоретичних та експериментальних досліджень НВЧ-діелектричних резонаторів з відкритими границями. Показано, що вони можуть бути використані для вимірювання параметрів діелектриків при опроміненні гамма-випромінюванням або пучком заряджених частинок. Проведено аналіз факторів, що впливають на точність вимірювань. 